\title{
OS IMPACTOS DO FRACIONAMENTO DE INVESTIMENTOS EM BOLSAS DE PESQUISA NO ENSINO PÚBICO
}

\author{
THE IMPACTS OF THE FRACTIONATION OF INVESTMENTS IN RESEARCH SCHOLARSHIPS
}

IN PUBLIC EDUCATION

\begin{abstract}
João Francisco Greff do Amaral
Universidade Regional Integrada do Alto Uruguai e das Missões, Santo Ângelo, RS, Brasil, joao.francisco. amaral@hotmail.com
\end{abstract}

Aline Fernanda Rocha Rocha (iD

Universidade Regional Integrada do Alto Uruguai e das Missões, Santo Ângelo, RS, Brasil, rochaalyne@ hotmail.com

Bianca Ariadne Santos da Rosa ic

Universidade Regional Integrada do Alto Uruguai e das Missões, Santo Ângelo, RS, Brasil, biancaadarosa@ gmail.com

Luana da Fonseca Patias

Universidade Regional Integrada do Alto Uruguai e das Missões, Santo Ângelo, RS, Brasil, luanafpatias0212@gmail.com

DOI: http://dx.doi.org/10.31512/missioneira.v31i1.58

Recebido em: 10/06/2019

Aceito em: 12/06/2020

Resumo: O presente artigo propõe-se discutir os cortes no investimento de bolsas de pesquisa na graduação e na pós-graduação. Partindo do pressuposto de Freire (1968/2015) entendemos que a educação é um caminho de libertação e construção crítica para uma nação. Doravante, buscamos sustentar uma revisão bibliográfica, consultando sistematicamente livros e periódicos sobre o fracionamento de investimentos em educação e ciência no Brasil. Em suma, compreendemos que o enfraquecimento da ciência no Brasil tende a forçar os jovens intelectuais a buscar, fora do país, aporte e fomento para desenvolver pesquisas e produzir conhecimento.

Palavras-chave: Educação. Ensino Superior. Realidade Brasileira.

\begin{abstract}
This paper aims to discuss the cuts in investment of research grants in undergraduate and postgraduate studies. From the assumption of Freire (1968/2015) we understand that education is a path of liberation and critical construction for a nation. Henceforth, we seek to support a literature review by systematically consulting books and periodicals on the fractionation of investments in education and science in Brazil. In short, we understand that the weakening of science in Brazil tends to force young intellectual to seek, abroad, funding and support to develop research and produce knowledge.
\end{abstract}

Keywords: Education. Higher education. Brazilian reality. 


\section{Introdução}

No momento atual, o Brasil passa por um período conflituoso em que a sociedade mostra-se ambivalente em ideais políticos. Sujeitos encontram-se desorientados com o atual sistema político, o qual tem realizado cortes em áreas fundamentais como educação, cultura e saúde, gerando liquidez em questões socioculturais.

Deste modo, a disciplina de Realidade Brasileira apresenta-se com a finalidade de provocar discussões e eliciar analises da contemporaneidade, envolvendo fatos históricos que contribuíram para o contexto atual, gerando reflexões sobre economia, cultura, política, ciência e tecnologias, propiciando aos alunos averiguar as origens de problemas socioculturais, assim como explorar os impasses da economia brasileira. Através dessa proposta, a disciplina proporciona ao estudante conhecimentos e reflexões sobre fatos históricos e eventos atuais, permitindo ao acadêmico compreender o cenário e integrar-se do mesmo.

Em vista disso, o presente artigo fora proposto na disciplina de Realidade Brasileira, e se propõe discutir os cortes realizados na educação, mais especificamente, cortes efetuados no ensino superior e pós-graduação, nas bolsas e financiamentos de estudo, na ciência e tecnologia.

Inicialmente, consideraremos o pressuposto de educação a partir da perspectiva de Paulo Freire. Para tal, educação vai além do processo de ensino-aprendizagem, educação é humanizar, é a interação entre as pessoas, é dar ao sujeito recursos para reflexão e transformação de seu social e cultural, transformar a si e ao seu meio. Transformar realidades. (ECCO;NOGARO, 2015, p. 3526).

Freire (2015/1968) conta-nos sobre um modelo de educação que preconize a autonomia do sujeito em face do seu processo de aprendizagem. Todavia, um aprender atravessado pela aquisição paulatina de uma "consciência crítica".

Entretanto, tendo conhecimento do processo histórico educacional brasileiro, percebese que este modelo de educação está distante de nossas realidades. Frisa-se assim, a importância de programas assistenciais (PROUNI e FIES, por exemplo) criados a fim de proporcionar maior igualdade de classes dentro das universidades, criados para sujeitos que eram até então privados de educação. Por um longo período, o ensino proporcionado a jovens filhos de classes trabalhadoras era apenas manual, para que dessa maneira fossem mantidos tais jovens em trabalhos rurais e industriais. $\mathrm{O}$ ensino superior de qualidade era apenas destinado a sujeitos filhos de grandes proprietários, investidores, ou seja, filhos da elite. (MOREIRA;BRISOLA, 2018, p 48).

Os programas de financiamento e bolsas estudantis têm agido como forma de proporcionar a sociedade vulnerável os mesmo direitos obtidos pelas classes cujo capital 
João Francisco Greff do Amaral et al.

econômico é maior. Através desses, é possível promover educação superior para maior número de jovens, os quais tenham o desejo de qualificarem-se profissionalmente em áreas cientificas e do mesmo modo tenham a oportunidade de um estudo qualitativo, bem como melhor qualidade de vida em sociedade.

No desenrolar da educação superior, além de programas assistenciais de financiamento, para maior desenvolvimento da ciência, a partir do ano 1950 (MAROSINI, 2009, p. 28) tornam-se viáveis estratégias para o desenvolvimento de pesquisas nas universidades do país, as quais se originam com o desígnio de estimular o avanço da ciência e da pesquisa científica, desenvolvendo pesquisadores.

Desde então, programas de iniciação cientifica no ensino superior, tal como em pósgraduação foram desenvolvidos e ganharam força no ramo da ciência. Bolsas de pesquisas na pós-graduação, além de proporcionar maior conhecimento cientifico ao sujeito que tem o interesse em desenvolver cientificamente em determinado assunto, proporciona aos mesmos inserção no desenvolvimento de pesquisas, programas e projetos de criação os quais são de extrema importância no desenvolvimento sociocultural de uma sociedade.

Assim, considerando a importância de tais programas, o presente artigo contextualizará os efeitos gerados socialmente aos jovens, assim como para as universidades públicas e sociedade em geral a partir dos cortes efetuados nos investimentos de bolsas de pesquisa na pós-graduação.

\section{Estratégias metodológicas}

Inicialmente, na disciplina de Realidade Brasileira, os estudantes foram divididos em grupos. Conseguinte, os autores do presente artigo, paulatinamente, delinearam a temática de pesquisa a partir de alguns encontros esporádicos onde se propuseram a discutir os temas sobre educação.

Não obstante, decidimos fazer uma breve revisão sistemática da literatura sobre educação, bem como, uma pesquisa bibliográfica dos artigos publicados recentemente e que tivessem em seu escopo o tema da redução de investimento em pós-graduação stricto senso e lato senso no sistema de ensino superior público brasileiro. Doravante, os artigos revisados foram encontrados através de revistas impressas e de publicações alocadas na plataforma do Google Acadêmico.

\section{Desenvolvimento}

$\mathrm{Na}$ ultima década, o Brasil avançou com a expansão de pesquisas e inovação, investimentos em programas de graduação e pós-graduação foram desenvolvidos, 
aparentemente o Brasil estava caminhando para um futuro prospero. Todavia, sem a destinação de aporte orçamentário pelo Estado brasileiro não há como desenvolver, aprimorar ou simplesmente manter os programas e as instituições que possuímos atualmente. É por esta situação que estamos passando, após uma fase de desenvolvimento, o Brasil parou de progredir e começou a regredir com pensamentos da idade média.

Não obstante, o Brasil continua com o ideal de desenvolvimento econômico, não é necessário desenvolver tecnologia dentro do país, a intensão é exportar mentes pensantes para posteriormente importar produtos de valor agregado. Em todo caso, Buarque (1993) discorre sobre os dez erros cometidos pela sociedade brasileira ao longo de sua busca por uma modernidade. Contudo, dentre os erros apontados, estaria, justamente, o foco no desenvolvimento econômico, assim, culminandono agenciamento precário de desenvolvimento em setores como educação e saúde (BUARQUE, 1993).

Desta forma, o financiamento da educação superior passou a ser considerado um gasto social muito elevado, não está dentro das prioridades de destinações de recursos do Brasil. Assim, decorreu no país não só uma tendência a problematização sobre a oferta do ensino superior público e a tentativa de desmonte através da limitação orçamentária, como também a ampliação e o fortalecimento deste nível de ensino no âmbito privado.

Ao observar as políticas públicas, percebe-se que os programas que visam o acesso à educação superior apresentam incentivo e fortalecimento ao setor privado de ensino. Esses programas que foram desenvolvidos pelos governos anteriores, apesar de se configurarem como políticas públicas favoráveis a democratização do acesso a universidades, apoiam-se no discurso sob promessa de diminuição das desigualdades sociais no país, mas acaba atendendo os interesses do sistema capitalista, sempre preocupado com o viés econômico, uma vez que favorece exclusivamente o setor privado de ensino. As universidades públicas nunca foram opções para todos, e atualmente o acesso ao curso superior está sendo delimitado por ações governamentais.

O Decreto $\mathrm{n}^{\circ}$ 9.741, de 29 de março de 2019, contingenciou R\$ 29.582 bilhões do Orçamento Federal de 2019, sendo 25\% deste montante do Ministério da Educação (MEC), assim, cada vez menor é o recurso destinado à educação (MARTINS, 2019, p.2).

Com o bloqueio de R\$ 2.158 bilhões do valor definido na Lei Orçamentária Anual (LOA), do total de recursos estimados de R $\$ 5.105$ bilhões, o Ministério da Ciência Tecnologia Inovações e Comunicações (MCTIC) ficará com apenas R 2.947 bilhões, o que representa 42,27\% dos recursos de investimento previstos para o ano de 2019 (MARTINS, 2019, p.3).

O Conselho Nacional de Desenvolvimento Científico e Tecnológico (CNPq), que enfrenta o terceiro ano consecutivo de queda nas verbas a ele destinadas, no presente exercício 
João Francisco Greff do Amaral et al.

prevê contar com a disponibilidade de recursos orçamentários somente até setembro, colocando em risco o pagamento a cerca de 80 mil bolsistas pesquisadores.

No Brasil, 80\% das pesquisas em ciência e tecnologia estão ligadas a programas de pós-graduação de universidades públicas. No entanto, com os cortes de recursos federais, que acontecem desde 2017, diversas pesquisas estão em risco. De 2010 a 2018, o orçamento para ciência e tecnologia passou de R \$ 10 bilhões para R \$ 1,4 bilhão. No Brasil, praticamente só há produção de pesquisa científica em universidades públicas e, nas empresas, apenas a Petrobras e indústrias farmacêuticas realizam investimento relevante nesta área. Para diversos bolsistas, esta é a única fonte de renda. O pagamento de bolsas de pesquisa garante a continuidade de pesquisas relevantes para o desenvolvimento científico e tecnológico nacional (MARTINS, 2019, p.3).

Os dois principais ministérios (MEC e MCTIC) que mundialmente possibilitam o desenvolvimento e a transformação do País numa potência, aqui estão limitados a um pequeno orçamento. Esta realidade dificulta estabilidade da educação e da pesquisa, o que não permite tornar o Brasil referência em desenvolvimento tecnológico e passar a ser um país desenvolvido.

Essa atual politica de sucateamento das universidades públicas apresenta-se como necessária e acomoda-se atrás de uma promessa para os cofres públicos. Contudo, isto nos sugere que a educação não está entre as prioridades governamentais.

Frente a uma estratégia de manobra da atual presidência de 2019, como descrevem várias reportagens, entre elas, alguns autores como Pereira (2019) e Borges (2019), abordam primeiramente os cortes como uma defesa a determinadas linhas de pensamentos, vinda das áreas das ciências humanas. Para se falar sobre isso é essencial voltar o pensamento para o nosso passado e visualizar a falta dessa consciência em nossa própria cultura. Não é de hoje que uma negligencia em três partes fundamentais do nosso estado é afetada, sendo elas: segurança, saúde e educação. O seguinte trecho de uma das reportagens de Pereira (2019, s/p.) demonstra o exemplo:

Quando a ideologia suplanta o bem comum, o resultado é o atraso. Nas últimas duas semanas, o Ministério da Educação anunciou mais duas medidas guiadas não pelas boas regras de gestão, mas, sim, pela visão retrógrada de sociedade concebida pelo governo de Jair Bolsonaro. O alvo, dessa vez, foram as universidades, por essência locais onde deve imperar o livre pensamento e a troca de ideias sem qualquer risco de represálias a quem não estiver alinhado com a ideologia do governo de plantão.

Ao mencionar, é cabível analisar que uma sociedade alienada não consegue por si própria enxergar a culpabilidade quanto à responsabilidade nessas partes como, por exemplo, o que está previsto no art. 205 da Constituição Federal, Brasil (1990) onde ensaia em outras palavras que o dever da educação é preocupação do Estado, escola, família e sociedade. 
Quando se frisa a responsabilidade deve-se tirar a culpa somente de um governo que foi eleito pelo povo, sendo ao mesmo tempo o reflexo desse.

Para que a Educação e até mesmo outras áreas bases sejam vista com relevância é necessário que haja uma reforma na mesma para que se construam sujeitos pensantes, cidadãos munidos de conhecimentos, que reivindiquem seus direitos, bem como, os exerçam. E dentre as diferentes ciências que se encontra num currículo escolar para aguçar esses pontos críticos e reflexivos, as ciências humanas, vista como o conjunto de conhecimentos do ser em social é de extrema importância para nossa história passado/presente/futuro. E quando se fala em social automaticamente se fala em Educação. No entanto, para Martins (2001, p. 550):

[...] a educação é determinada e determinante pela estrutura social é considerar que esta não vive isolada, mas sim que a educação é uma práxis, isto é, a educação é uma ação teórico-prática, que se manifesta na realidade concreta da vida social como processos de ensino-aprendizagem, por meio dos quais se procura efetivar o ideal de homem segundo as necessidades de uma determinada formação econômica e social ou, valendose da liberdade humana, questiona o ideal vigente e lhe propõe outros, mobilizando as vontades e as convicções de sujeitos individuais e grupos sociais até transformar suas ações.

Em vista disso, ao pensar sobre os currículos escolares, sejam eles do ensino fundamental ou superior, enfoca-se em um método desadaptado, criando sujeitos repetidores de palavras, fatos e fórmulas matemáticas, e, não pensantes criadores de ideias, debates e hipóteses. Uma base criada de memorização sem que o conhecimento seja experienciado com a realidade.

Para Paulo Freire (1979) é a partir das relações do homem com a realidade, que o sujeito experiência o conhecimento, através de mecanismos mentais para estar com ela e estar nela, cria, recria e decide, na mesma medida que o individuo dinamiza seu mundo é capaz de transformar as épocas históricas. Por isso salienta-se a necessidade de uma educação crítica, como uma forma do homem se integrar em seu meio, e para isso também serve a educação, para a decisão conforme sua responsabilidade politica e social. Uma educação, portanto, que esteja de acordo com o diálogo constante com o outro, pois é através disso que o sujeito se identifica e vive os métodos e processos científicos.

É importante levar em consideração que muitas linhas de interesses advindas de países exteriores interferem nas bases. Um povo ignorante é um bom país escravo. $\mathrm{O}$ Brasil, por exemplo, é muito rico em solo fértil, e todo o sistema politico na parte agrária é praticamente exportado para fora, isso faz com que permaneçamos inertes de nossas riquezas e possibilidades. Ainda que seja um pensamento utópico, acredita-se que a educação seja por fim uma das maneiras de transformar o futuro da nação. 
A educação como base de uma nação foi uma proposta articulada durante a ascensão iluminista. Rousseau (1762/2015) ao discorre sobre "O contrato social” inferia que a educação é uma ferramenta capaz de sustentar o crescimento de um país.

Em todo caso, poderíamos questionar o lugar que a educação ocupa quando se patenteiam governos políticos que não priorizam as bases, as minorias que sustentam o país. Imagina-se que um dos problemas mundiais seja a fome, e que o país futuramente seja mais independente, tudo isso fará com que outros países precisem de suporte para exportar do Brasil os recursos naturais, e que isso não seja roubado como a nossa Amazônia esta atualmente sendo. Sonha-se que a educação como um todo seja essa fonte de riqueza e que através das pesquisas cientificas das soluções de problemáticas se amplifique para outras áreas que estejam vulneráveis nos dias atuais.

\section{Considerações finais}

Compreendemos que a educação alicerçada no preceito "coletivo-crítico-social" revela-se uma ferramenta possível no crescimento coletivo de um país. Práticas pedagógicas calcadas na potencialização e na produção de conhecimentos tendem a instrumentalizar e fortalecer as bases de um país no seguimento de uma epistemologia científica centrada no "bem-estar social".

Sem investimento em educação, os brasileiros são tomados de uma perspectiva de evolução do Brasil. As noticias de cortes e de afronta às universidades tornam-se banais e, sem forças para transformar o futuro, o coletivo deixa-se calar.

Enfrentamos, atualmente, a consequência de uma elite brasileira que foi afrontada quando a população de baixa renda teve a possibilidade de ir para uma universidade, não querem frequentar os mesmos ambientes que pobres e negros frequentam, assim estão tirando as oportunidades de pessoas carentes.

Ao invés de avançarmos a partir da educação, entendendo a pesquisa e extensão como impulso à tecnologia, desenvolvimento e fortalecendo a imagem do Brasil, as estratégias governamentais atuais apresentam a privatização, enfraquecimento no ensino público e retirada de direitos ao acesso e permanência aos estudantes brasileiros.

Em suma, entendemos que possivelmente o Brasil enfrentará, nos próximos anos, uma migração em massa de sua comunidade científica. A exportação do intelecto jovem brasileiro tornar-se-á banal, tal como as notícias atuais de redução/cortes de investimento nas bolsas de graduação e pós-graduação. 


\section{Referências}

BORGES, Helena. Bolsonaro defende cortes em cursos de Humanas e diz que dinheiro do contribuinte deve ir para 'leitura, escrita e fazer conta'. O Globo, 2019. Disponível em: https://oglobo.globo.com/sociedade/bolsonaro-defende-cortes-em-cursos-de-humanas-dizque-dinheiro-do-contribuinte-deve-ir-para-leitura-escrita-fazer-conta-23623980. Acesso em: 14 de out. de 2019.

BUARQUE, Cristovam. A revolução nas prioridades. 2. ed. Brasília: Centro Gráfico do Senado Federal, 1993.

BRASIL. Constituição (1988). Constituição da República Federativa do Brasil: promulgada em 5 de outubro de 1988. 4. ed. São Paulo: Saraiva, 1990.

ECCO, I.; NOGARO, A. A educação em Paulo Freire como processo de humanização. 2015. Disponível em: https://educere.bruc.com.br/arquivo/pdf2015/18184_7792.pdf. Acesso em: 27 set, 2019.

FREIRE, Paulo. Pedagogia do oprimido. São Paulo: Paz e Terra, 1968/2015.

MARTINS, Vinicius. Educação, ciência e tecnologia: como desenvolver o Brasil sem investimento. Revista Thema, Pelotas, 2019.

FREIRE, Paulo. Educação e mudança. 12. ed. Paz e Terra. Rio de Janeiro, 1979.

MARTINS, M.F. Gramsci. Os intelectuais e suas funções científico- filosófica, educativocultural e política. Pro-Posições, v. 22, n. 3, p. 131-148, 2011. Disponível em: https:// periodicos.sbu.unicamp.br/ojs/index.php/proposic/article/view/8643249. Acesso em: 11 out.2019.

MOREIRA, Ana Carolina Gonçalves Da Silva; BRISOLA, Elisa Maria Andrade. Universidade e cidadania: considerações sobre o direito social à educação. Temporalis, Brasília (DF), ano 18, n. 35, jan./jun. 2018.

MOROSINI, Marília Costa. A Pós-graduação no Brasil: formação e desafios. RAES, v. 11, n. 1, nov. 2009.

ROUSSEAU, Jean-Jacques. O contrato social. Trad. Paulo Neves. Porto Alegre: LePM Pockt, 2015.

SOUZA, Adnna Raquel Araújo de. Educação me tempos de contrarreforma: identificando as implicações da política de ajuste fiscal no Ensino Superior brasileiro e os seus rebatimentos na Assistência Estudantil, 2019. 
João Francisco Greff do Amaral et al.

PEREIRA, Cilene. A balbúrdia está no governo: O corte de verbas para as universidades federais e também para os cursos de Filosofia e Sociologia mostra que Bolsonaro quer eliminar a atual ideologia que há no ensino para impor a sua própria doutrinação. Istoé, 2019. Disponível em: https://istoe.com.br/a-balburdia-esta-no-governo/. Acesso em: 11 out. 2019. 